\title{
Macrophages induce an allergen-specific and long-term suppression in a mouse asthma model
}

\author{
J.L.M. Vissers*, B.C.A.M. van Esch*, G.A. Hofman* and A.J.M. van Oosterhout*,*
}

ABSTRACT: Increasing evidence suggests that macrophages (M $\phi)$ play a crucial downregulatory role in the initiation and progression of allergic asthma. Recently, the current authors demonstrated that ovalbumin (OVA)-loaded $M \phi$ (OVA-M $\phi$ ) suppress subsequent OVA-induced airway manifestations of asthma and that this effect could be potentiated upon selective activation. In the present study, the authors further delineated the underlying pathway by which $M \phi$ exert this immunosuppressive effect.

To examine the migration of OVA-M $\phi$, cells were labelled with 5 'chloromethylfluorescein diacetate (CMFDA) and were administered (i.v.) into OVA-sensitised BALB/c mice. After $20 \mathrm{~h}$, the relevant organs were dissected and analysed using fluorescent microscopy. Allergen-specificity was investigated by treating OVA-sensitised mice with keyhole limpet haemocyanin (KLH)-M $\phi$ activated with immunostimulatory sequence oligodeoxynucleotide (ISS-ODN). By lengthening the period between treatment and challenge to 4 weeks it was examined whether OVA-M $\phi$ exerted an immunosuppressive memory response.

Strikingly, CMFDA-labelled $\mathrm{M} \phi$ were not trapped in the lungs, but migrated to the spleen. ISSODN-stimulated $\mathrm{KLH}-\mathrm{M} \phi$ failed to suppress OVA-induced airway manifestations of asthma. Moreover, treatment with ISS-ODN-stimulated OVA-M $\phi$ was still effective after lengthening the period between treatment and challenge.

These data demonstrate that allergen-loaded macrophages can induce an indirect immunosuppressive response that is allergen-specific and long lasting, which are both hallmarks of a memory lymphocyte response.

KEYWORDS: Allergy, interleukin-10, macrophages, regulatory T-cells, T-helper cell type 2 lymphocytes

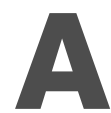
llergic asthma is characterised by reversible airway obstruction, increased levels of allergen-specific immunoglobulin (Ig)$\mathrm{E}$, chronic airway inflammation and persistent airway hyperreactivity (AHR). Allergic asthma is driven and maintained by the persistence of a subset of chronically activated memory T-cells [1, 2]. The maintenance of immunological homeostasis in the respiratory tract requires finetuning of T-cell activation, in order to induce a sufficient inflammatory response against inhaled pathogens, while avoiding excessive responses. Increasing evidence suggests that macrophages $(\mathrm{M} \phi)$ play a pivotal role in both the potentiation and the suppression of inflammatory responses [3].

$\mathrm{M} \phi$ trigger the immune responses against microbial pathogens by secreting pro-inflammatory cytokines, such as interleukin (IL)-1, IL-6 and tumour necrosis factor (TNF)- $\alpha[4,5]$. Moreover, by releasing IL-12 they can specifically skew immune responses towards T-helper cell type 1 (Th1) responses [6-8]. Though $\mathrm{M} \phi$ favour the induction of Th1 responses [9, 10], it has also been demonstrated that $\mathrm{M} \phi$ can induce differentiation towards Th2 lymphocytes [11, 12]. To exert immunosuppressive responses $\mathrm{M} \phi$ secrete anti-inflammatory mediators, such as prostaglan$\operatorname{din}(\mathrm{PG}) \mathrm{E}_{2}$, transforming growth factor (TGF)- $\beta$, IL-10 and nitric oxide [3, 5, 13].

Alveolar $\mathrm{M} \phi$ represent the most predominant immune effector cells in the alveolar spaces and conducting airways [3]. By secreting proinflammatory cytokines and chemokines alveolar $\mathrm{M} \phi$ direct the recruitment and activation of inflammatory cells, while they also play a key role in dampening immune responses against nonpathogenic antigens $[5,14]$. Alveolar M $\phi$ have

\section{AFFILIATIONS}

*Dept of Pharmacology and Pathophysiology, Faculty of Pharmaceutical Sciences, Utrecht University, Utrecht and \# Laboratory of Allergology and Pulmonary Diseases, Dept of Pathology and Laboratory Medicine, University Medical Center Groningen, University of Groningen, Groningen, the Netherlands.

\section{CORRESPONDENCE}

A.J.M. van Oosterhout

Laboratory of Allergology and

Pulmonary Diseases

Dept Pathology and Laboratory Medicine

University Medical Center Groningen Hanzeplein 1

PO Box 30.001

9700 RB Groningen

The Netherlands

Fax: 31503610570

E-mail: A.J.M.van.Oosterhout

@path.umcg.nl

Received:

July 292004

Accepted after revision:

August 022005

SUPPORT STATEMENT

This study was supported by research grants 3.2.00.48 (J.L.M.V.) from The Dutch Asthma Foundation and by Stichting Astma Bestrijding (B.C.A.M.V.E).

European Respiratory Journal Print ISSN 0903-1936 Online ISSN 1399-3003 
been shown to suppress T-lymphocyte proliferation in vitro $[15,16]$ and antigen presentation functions of dentritic cells in vitro and in vivo [17]. Although depletion of alveolar $\mathrm{M} \phi$ potentiated $\operatorname{IgE}$ antibody production in response to inhaled allergen [18] and adoptive transfer of alveolar $\mathrm{M} \phi$ suppresses AHR [19], the underlying cellular and molecular mechanisms remain to be elucidated [3].

Previously, the current authors developed a mouse model in which allergen-loaded $\mathrm{M} \phi$ suppressed allergen-induced airway manifestations [20]. The anti-inflammatory effects of $\mathrm{M} \phi$ could be potentiated by activating the M $\phi$ with the selective toll-like receptor (TLR)-9 or -4 ligands immunostimulatory sequence oligodeoxynucleotide (ISS-ODN) or lipopolysaccharide (LPS), respectively, ex vivo [21]. Interestingly, IL10 is upregulated in these activated $\mathrm{M} \phi$ and plays a crucial role in the anti-inflammatory effects of $\mathrm{M} \phi$ in vivo [21]. In this study, the mechanisms underlying these anti-inflammatory effects were investigated in more detail. Strikingly, after administration (i.v.), allergen-loaded $M \phi$ migrated to the spleen. As a consequence, the authors investigated whether $\mathrm{M} \phi$ induce, in the spleen, an indirect allergen-specific and long-term suppressive response.

\section{METHODS}

\section{Animals}

Animal care and use were performed in accordance with the guidelines of the Dutch Committee of Animal Experiments. Specific pathogen-free (according to the Federation of European Laboratory Animal Science Associations [22]) male BALB/c mice (6-weeks old) were purchased from Charles River (Maastricht, The Netherlands). The mice were housed in macrolon cages in a laminar flow cabinet. All mice were provided with food and water ad libitum.

\section{Materials}

OVA (grade V), purified LPS from Escherichia coli 0111:B4, and methacholine (acetyl- $\beta$-methylcholine chloride) were purchased from Sigma-Aldrich (St. Louis, MO, USA). Keyhole limpet haemocyanin (KLH) was obtained from Calbiochem (San Diego, CA, USA). Fluorescent dye 5'chloromethylfluorescein diacetate (CMFDA) was acquired from Molecular Probes Europe BV (Leiden, The Netherlands). CpG-containing phosphorothioate ISS-ODN was synthesised by Isogen Bioscience BV (Maarsen, The Netherlands). The ISS-ODN used had the sequence 5'-TGACTGTGAACGTTCGAGATGA-3' [23].

\section{Loading and stimulation of macrophages}

Peritoneal $\mathrm{M} \phi$ were isolated from naïve BALB/c mice as described previously [20]. Subsequently, $1 \times 10^{7} \mathrm{M} \phi \cdot \mathrm{mL}^{-1}$ were loaded with $2 \mathrm{mg} \cdot \mathrm{mL}^{-1} \mathrm{OVA}$ or $2 \mathrm{mg} \cdot \mathrm{mL}^{-1} \mathrm{KLH}$ and were stimulated with $10 \mu \mathrm{g} \cdot \mathrm{mL}^{-1}$ LPS or $3 \mu \mathrm{g} \cdot \mathrm{mL}^{-1}$ ISS-ODN [21]. After incubation for $3 \mathrm{~h}$ at $37^{\circ} \mathrm{C}$ and $5 \% \mathrm{CO}_{2}$, the $\mathrm{M} \phi$ were extensively washed to remove all residual soluble OVA, LPS, and ISS-ODN.

\section{Sensitisation, treatment and challenge}

Mice were sensitised to OVA by active sensitisation with 7 i.p. injections of $10 \mu \mathrm{g}$ OVA in $0.5 \mathrm{~mL}$ pyrogen-free saline on alternate days [24]. Treatment was performed 17 days after the last sensitisation by administration (i.v.) of $3 \times 10^{5} \mathrm{M} \phi$
(OVA-loaded or KLH-loaded) in $50 \mu$ saline. As an additional control group, mice were i.v. injected with $50 \mu \mathrm{l}$ saline. After 1-4 weeks post treatment, mice were exposed to OVA ( $2 \mathrm{mg} \cdot \mathrm{mL}^{-1}$ saline) aerosol challenges for $5 \mathrm{~min}$ on eight consecutive days.

\section{Fluorescent labelling and localisation of macrophages}

A total of $1 \times 10^{7} \mathrm{M} \phi \cdot \mathrm{mL}^{-1}$ were loaded with OVA $\left(2 \mathrm{mg} \cdot \mathrm{mL}^{-1}\right)$ and stimulated with ISS-ODN $\left(3 \mu \mathrm{g} \cdot \mathrm{mL}^{-1}\right)$ for $3 \mathrm{~h}$ at $37^{\circ} \mathrm{C}$ and $5 \% \mathrm{CO}_{2}$. At the last $30 \mathrm{~min}, 10 \mu \mathrm{M}$ CMFDA was added to the $\mathrm{M} \phi$, the $\mathrm{M} \phi$ were then extensively washed. To test the labelling efficiency, $1 \times 10^{5} \mathrm{CMFDA}$-labelled $\mathrm{M} \phi \cdot \mathrm{mL}^{-1}$ were cultured in 96-well round-bottomed plates (Greiner Bio-One $\mathrm{GmbH}$, Kremsmuenster, Austria) in Roswell Park Memorial Institute medium-1,640 enriched with $2 \%$ foetal calf serum, penicillin/ streptomycin (all GIBCO BAL division of Invitrogen, Breda, The Netherlands) and $50 \mu \mathrm{M} \quad \beta$-mercaptoethanol (SigmaAldrich). After $20 \mathrm{~h}$, the $\mathrm{M} \phi$ were harvested and cytospins of these M $\phi$ were analysed using fluorescent microscopy. Subsequently, OVA-sensitised mice were treated (i.v.) with $3 \times 10^{5} \mathrm{M} \phi$. After $20 \mathrm{~h}$, blood, lungs, spleen, lymph nodes (axillary, brachial, thoracic), liver and kidneys were collected. Several $6-\mu \mathrm{m}$ thick cryosections of the tissues were analysed using fluorescent microscopy.

\section{Measurement of airway responsiveness in vivo}

Airway responsiveness was measured in conscious, unrestrained mice using barometric whole-body plethysmography by recording respiratory pressure curves (Buxco corp., EMKA Technologies, Paris, France) in response to inhaled methacholine (ranging from $0-50 \mathrm{mg} \cdot \mathrm{mL}^{-1}$ methacholine). Airway responsiveness was expressed in enhanced pause (Penh), as described previously [25].

\section{Determination of ovalbumin-specific immunoglobulin-E levels in serum}

After measurement of in vivo airway responsiveness, mice were sacrificed by injection of $1 \mathrm{~mL} \mathrm{10 \%}$ urethane (i.p., SigmaAldrich). Mice were bled by cardiac puncture. Subsequently, serum was collected and stored at $-70^{\circ} \mathrm{C}$ until analysis. Serum OVA-specific IgE was measured as described previously [26]. A reference standard was obtained by i.p. immunisation of mice with OVA and arbitrarily assigned a value of 1,000 experimental units $\cdot \mathrm{mL}^{-1}\left(\mathrm{EU} \cdot \mathrm{mL}^{-1}\right)$. The detection level of the IgE ELISA was $0.5 \mathrm{EU} \cdot \mathrm{mL}^{-1}$ for IgE.

\section{Analysis of the cellular composition in the bronchoalveolar lavage fluid}

Bronchoalveolar lavage (BAL) was performed immediately after bleeding of the mice by lavage of the airways through a tracheal cannula with $1 \mathrm{~mL}$ saline $\left(37^{\circ} \mathrm{C}\right)$ containing $2 \mu \mathrm{g} \cdot \mathrm{mL}^{-1}$ aprotinine (Roche Diagnostics, Almere, The Netherlands) and $5 \%$ bovine serum albumin (Sigma-Aldrich). Cytokines in the supernatant of the first $\mathrm{mL}$ of the BAL fluid (BALF) were determined by ELISA. Subsequently, mice were lavaged a total of four times with $1 \mathrm{~mL}$ saline $\left(37^{\circ} \mathrm{C}\right)$. The cells in the BALF were pooled in cold phosphate-buffered saline (including those from the first $\mathrm{mL}$ ). Subsequently, cells in the BALF were differentiated into mononuclear cells (monocytes, $\mathrm{M} \phi$ and lymphocytes), eosinophils, and neutrophils as described previously [26]. 


\section{Cytokine ELISAs}

IL-5 ELISA (BD PharMingen, Alphen aan den Rijn, The Netherlands) was performed according to the manufacturer's instructions. The detection limit of the IL-5 ELISA was $10 \mathrm{pg} \cdot \mathrm{mL}^{-1}$.

\section{Statistical analysis}

All data are expressed as mean \pm SEM. The airway doseresponse curves to methacholine were statistically analysed by a general linear model of repeated measurements followed by post hoc comparison between groups. Data were log transformed before analysis to equalise variances in all groups. Statistical analysis on BALF cell counts was performed using the nonparametric Mann-Whitney U-test (2-tailed). For ELISA, results were analysed statistically using a t-test (2-tailed, homoscedastic). Results were considered statistically significant at the $\mathrm{p}<0.05$ level.

\section{RESULTS}

\section{Allergen-loaded macrophages migrate to the spleen}

Allergen-loaded $\mathrm{M} \phi$ suppress anti-inflammatory responses in a mouse model of allergic asthma [20,21]. To gain more insight in the underlying mechanism, the localisation of OVA-M $\phi$ after administration (i.v.) was examined. Peritoneal $\mathrm{M} \phi$ were loaded with OVA (OVA-M $\phi$ ) and stimulated with ISS-ODN. Subsequently these $\mathrm{M} \phi$ were labelled with the fluorescent dye CMFDA.

As a control, the CMFDA-labelled OVA-M $\phi$ were cultured for $20 \mathrm{~h}$ at $37^{\circ} \mathrm{C}$ and $5 \% \mathrm{CO}_{2}$ and the labelling efficiency was analysed. As shown in figures $1 \mathrm{a}$ ) and b), $20 \mathrm{~h}$ afters labelling $>95 \%$ of the $\mathrm{M} \phi$ were still fluorescent.

Additionally, OVA-sensitised mice were treated (i.v.) with $3 \times 10^{5}$ CMFDA-labelled OVA-M $\phi$. After $20 \mathrm{~h}$, the blood, lungs, spleen, lymph nodes (axillary, brachial, thoracic), liver and kidney were dissected and analysed for the presence of CMFDA-labelled M $\phi$. Analysing the different tissues, no CMFDA-labelled OVA-M $\phi$ was found throughout the lungs (fig. 1c), whereas labelled $\mathrm{M} \phi$ were clearly detectable in the spleen (fig. 1d-f). Staining with haematoxylin (not shown) revealed that most $(\sim 90 \%)$ CMFDA-labelled M $\phi$ were localised in the marginal zones of the spleen. No CMFDA-labelled $\mathrm{M} \phi$ were detectable in the blood or any other analysed tissue, including the main clearance sites; liver and kidney (data not shown).

Since OVA-M $\phi$ migrated to the spleen, it was hypothesised that these $M \phi$ can accomplish an indirect suppressive effect, most probably mediated by the induction of allergen-specific memory lymphocytes.

\section{Allergen-loaded macrophages induce an allergen-specific suppression}

Allergen-specificity was examined by treating OVA-sensitised mice with ISS-ODN-stimulated and KLH-loaded M $\phi$. In shamtreated mice, the airway responsiveness to increased concentrations of methacholine $\left(1.6-50 \mathrm{mg} \cdot \mathrm{mL}^{-1}\right)$ was significantly $(p<0.05)$ increased upon OVA inhalation challenge. As an example the airway hyperresponsiveness to $50 \mathrm{mg} \cdot \mathrm{mL}^{-1}$ methacholine is depicted in figure 2a. As compared with sham-treated mice, the increase in AHR was significantly $(\mathrm{p}<0.05$; up to $40 \%)$ suppressed upon treatment with ISSODN-stimulated OVA-M $\phi$ (fig. 2a). In contrast, ISS-ODNstimulated KLH-M $\phi$ failed to suppress the AHR to methacholine (fig. 2a).

Additionally, the analysis of serum OVA-specific IgE levels demonstrated that the OVA-specific IgE levels dramatically increased upon challenge in sham-treated mice (fig $2 b$ ). ISSODN-stimulated KLH-M $\phi$ were not capable of suppressing the upregulation of OVA-specific IgE (fig. 2b). As a control, ISSODN-stimulated OVA-M $\phi$ suppressed the upregulation of OVA-specific IgE for $68 \%(\mathrm{p}<0.01)$, as compared with shamtreated mice (fig. 2b).

In agreement with these results, ISS-ODN-stimulated KLH-M $\phi$ failed to suppress both the airway eosinophilia and IL-5 levels in the BALF (fig. 2c and d), whereas ISS-ODN-stimulated OVA-M $\phi$ significantly $(\mathrm{p}<0.05)$ suppressed these asthma manifestations $(89 \%$ and $83 \%$ compared with sham-treated mice, respectively).

\section{Activated ovalbumin-macrophage induce a long-lasting immunosuppressive effect}

By lengthening the time period between $\mathrm{M} \phi$ treatment and OVA inhalation challenge from 1 to 4 weeks, it was possible to investigate whether allergen-loaded $\mathrm{M} \phi$ induced memory suppressive effects. OVA-sensitised mice were treated with OVA-M $\phi$, LPS-stimulated OVA-M $\phi$, or ISS-ODN-stimulated
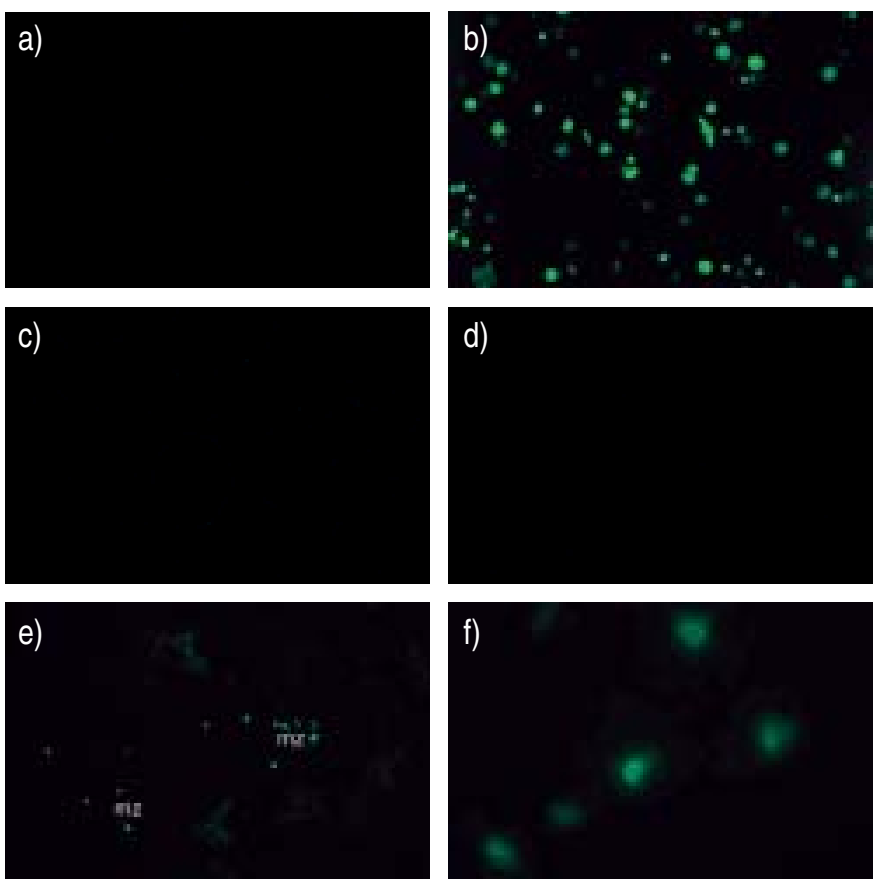

FIGURE 1. Immunostimulatory sequence oligodeoxynucleotide (ISS-ODN)stimulated ovalbumin (OVA)-macrophages (M $\$$ ) migrate to the spleen. ISS-ODNstimulated OVA-M $\phi$ were labelled with $5^{\prime}$ chloromethylfluorescein diacetate (CMFDA). As a control, unlabelled M $\phi$ and CMFDA-labelled $M \phi$ were cultured for $20 \mathrm{~h}$ at $37^{\circ} \mathrm{C}$ and $5 \% \mathrm{CO}_{2}$ and subsequently, cytospins of unlabelled $\mathrm{M \phi}$ (a) and CMFDA-labelled $M \phi(b)$ were analysed for labelling efficiency. OVA-sensitised mice were treated (i.v.) with CMFDA-labelled $M \phi(n=6 ; c$, e and f) or with saline $(n=3, d)$. After $20 \mathrm{~h}$, lungs (c) and spleen ( $d$, e and f) were dissected and analysed. mz: marginal zone. 

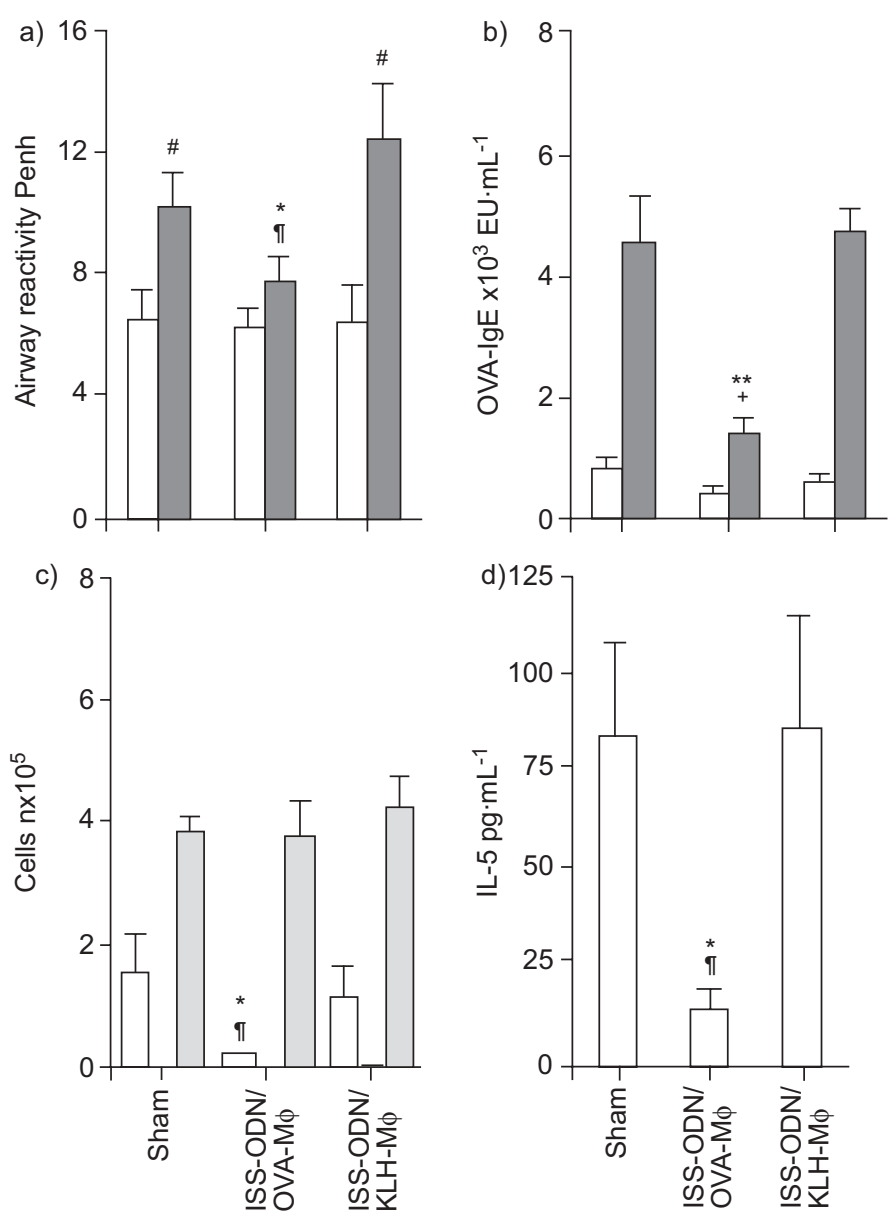

FIGURE 2. Allergen-loaded macrophages $(M \phi)$ induce an allergen-specific immunosuppressive response. Prior to the ovalbumin (OVA) challenge, OVAsensitised mice were treated (i.V.) with saline (sham), immunostimulatory sequence oligodeoxynucleotide (ISS-ODN)-stimulated OVA-M $\phi$ (ISS-ODN/OVA-M $\phi$ ), or ISSODN-stimulated keyhole limpet haemocyanin (KLH)-M $($ (ISS-ODN/KLH-M $\phi$ ). a) The airway hyperresponsiveness to aerosolised methacholine was measured before ( $\square$ ) and after ( $\square$ ) OVA inhalation challenge (expressed in enhanced pause: Penh). As representative for the methacholine dose response curve of all groups, the response to $50 \mathrm{mg} \cdot \mathrm{mL}^{-1}$ methacholine is depicted. b) Serum OVA-specific immunoglobulin $(\mathrm{Ig}) \mathrm{E}$ levels prior to $(\square)$ and after $(\square)$ challenge. The number of eosinophils $(\square)$, neutrophils $(\mathbf{\square})$ and mononuclear cells $(\square)$ in the c) bronchoalveolar lavage fluid (BALF), and d) interleukin (IL)-5 levels in the BALF after OVA challenge. Values are expressed as the mean $\pm \operatorname{SEM}(n=6-8$ per group). EU: experimental unit. ${ }^{*}: p<0.05$ compared with the same mice before OVA challenge. ${ }^{*}: p<0.05$ and ${ }^{* *}: p<0.01$ compared with sham-treated and OVAchallenged mice. ${ }^{\circ}: p<0.05$ and $^{+}: p<0.01$ compared with mice treated with ISS$\mathrm{ODN} / \mathrm{KLH}-\mathrm{M} \phi$ and OVA-challenged.

OVA-M $\phi$. After 4 weeks the mice were challenged by OVA inhalation (8 days) and, subsequently, the increase in airway responsiveness to methacholine was measured. In shamtreated mice the airway responsiveness to increased concentrations of methacholine $\left(1.6-25 \mathrm{mg} \cdot \mathrm{mL}^{-1}\right)$ was significantly $(p<0.01)$ increased upon OVA inhalation challenge. As an example the airway hyperresponsiveness to $25 \mathrm{mg} \cdot \mathrm{mL}^{-1}$ methacholine is depicted in figure 3a. After a 4-week interval between treatment and challenge, e.g. after a short-term interval, ISS-ODN-stimulated OVA-M $\phi$ significantly $(\mathrm{p}<0.05)$ suppressed the AHR for up to $48 \%$, as compared with shamtreated mice (fig. 3a).

After a long-term interval between treatment and challenge, OVA-M $\phi$ strongly suppressed $(75 \%, \mathrm{p}<0.05)$ the upregulation of serum OVA-specific IgE levels (fig. 3b). Ex vivo stimulation of OVA-M $\phi$ with LPS or ISS-ODN did not further suppress these OVA-specific IgE levels (fig. 3b).

Moreover, after a long-term interval between treatment and challenge ISS-ODN-stimulated OVA-M $\phi$ suppressed signifi-
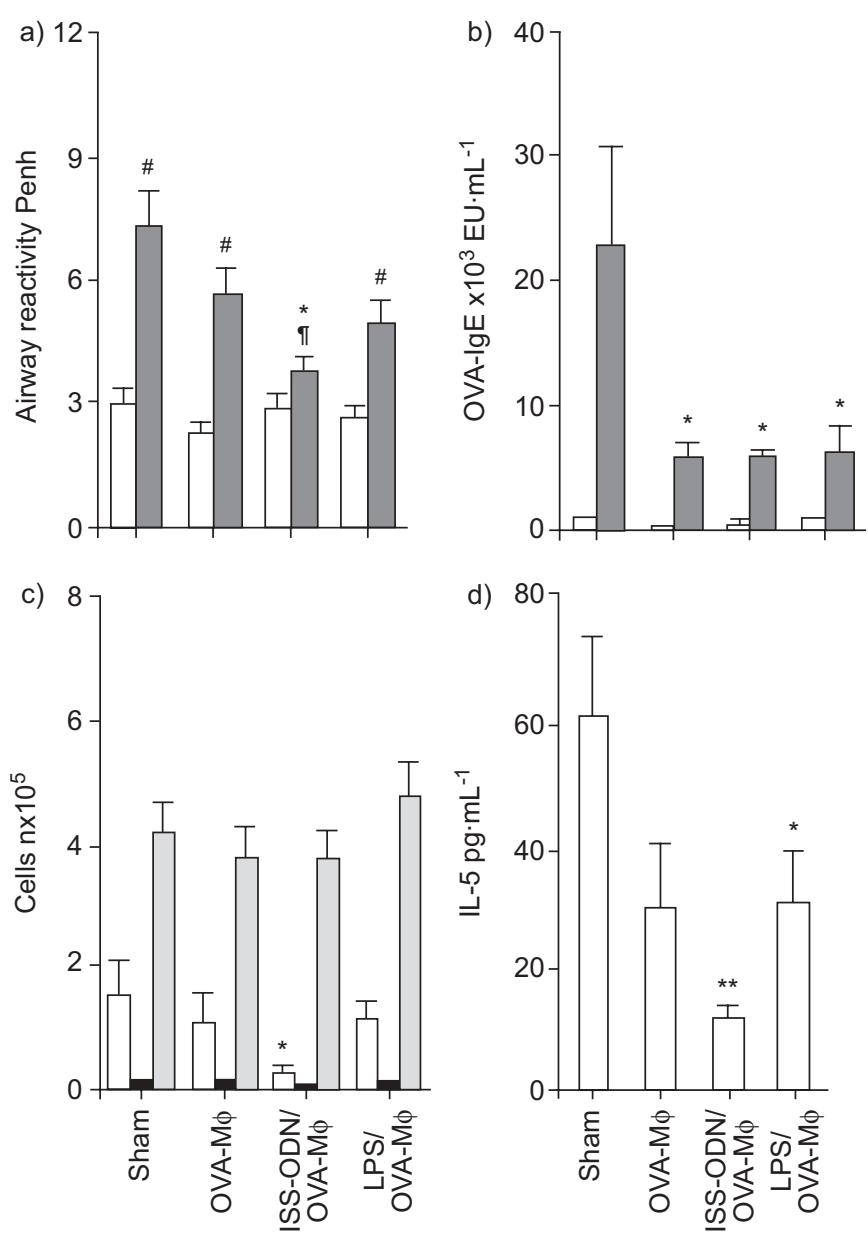

FIGURE 3. Immunostimulatory sequence oligodeoxynucleotide (ISS-ODN)stimulated ovalbumin macrophage (OVA-M $\phi$; ISS-ODN/OVA-M $\phi$ ) induce a longterm immunosuppressive response. OVA-sensitised mice were treated (i.v.) with saline (sham), OVA-M $\phi$, ISS-ODN/OVA-M $\phi$, or lipopolysaccharide (LPS)-stimulated OVA-M $\phi$ (LPS/OVA-M $\phi)$. After 4 weeks, these mice were challenged by OVA inhalation. a) The airway hyperresponsiveness to aerosolised methacholine was measured before $(\square)$ and after ( $\square$ ) OVA inhalation challenge. As representative for the methacholine dose response curve of all groups, the response to $25 \mathrm{mg} \cdot \mathrm{mL}^{-1}$ methacholine is depicted. b) OVA-specific immunoglobulin (Ig)E levels in serum prior to $(\square)$ and after ( $\square$ ) challenge. c) Number of eosinophils $(\square)$, neutrophils ( and mononuclear cells $(\square)$ in the bronchoalveolar lavage fluid (BALF) after OVA challenge. d) Interleukin (IL)-5 levels in the BALF after OVA challenge. Values are expressed as the mean \pm SEM ( $n=6-8$ per group). EU: experimental units. " : $p<0.05$ and ${ }^{*}: p<0.01$ compared with the same mice before OVA challenge; $*: p<0.05$ and **: $p<0.01$ compared with sham-treated and OVA-challenged mice. 
cantly $(\mathrm{p}<0.05)$ the influx of eosinophils into the lungs for $82 \%$, as compared with sham-treated mice (fig. 3c). In correlation with the numbers of eosinophils, the IL-5 levels in the BALF were significantly suppressed $(81 \%, \mathrm{p}<0.01)$ upon treatment with ISS-ODN-stimulated OVA-M $\phi$ (fig. 3d). LPS-stimulated OVA-M $\phi$ failed to suppress airway eosinophilia but suppressed significantly $(p<0.05)$ the IL-5 levels in the BALF for $51 \%$, compared with sham-treatment (fig. 3d).

\section{DISCUSSION}

Though it is suggested that $\mathrm{M} \phi$ play a pivotal role in the activation, as well as suppression of allergic asthma, the mechanism by which they exert these functions is still under debate [3]. Previously, the current authors demonstrated that allergen-loaded $\mathrm{M} \phi$ suppress anti-inflammatory responses in a mouse model of allergic asthma [20,21]. This current study shows that allergen-loaded $\mathrm{M} \phi$ migrate to the spleen and induce, locally, an allergen-specific and long-lasting immunosuppressive response, hallmarks of a memory lymphocyte response.

Using animal models of allergic asthma, it has been suggested that $\mathrm{M} \phi$ can exert a direct effect on the immunological homeostasis in the airways. Depletion of alveolar M $\phi$ increased the $\operatorname{IgE}$ responses [18] and adoptive transfer of alveolar $\mathrm{M} \phi$ abrogated AHR [19]. Recently, PYNAERT et al. [27] showed that spleen $\mathrm{M} \phi$, loaded with OVA and intratracheal-administered, suppressed airway eosinophilia, probably, by inducing a Th1mediated counter regulation in the lung $[8,27]$. In contrast, in the present study evidence was obtained for an indirect mechanism by which $\mathrm{M} \phi$ can suppress anti-inflammatory responses in the lung.

Using CMFDA-labelled $M \phi$, it was observed that intravenously-administered $\mathrm{M} \phi$ were not trapped in the lungs, but migrated to the spleen. Twenty hours after treatment, CMFDA-labelled $\mathrm{M} \phi$ were only detectable in the spleen, while no CMFDA-labelled M $\phi$ were found in the lungs or lymph nodes. This is in agreement with the homing of intravenousadministered $\mathrm{M} \phi$ and dendritic cells generated ex vivo, which transiently migrate to the lungs (within 2-3 h) followed by accumulation in the spleen and hardly in the lymph nodes [2831]. In addition, $>95 \%$ of interferon- $\gamma$-stimulated $M \phi$ reach the spleen within $5 \mathrm{~h}$ after i.v. injection, while less than $3 \%$ are detected in lung tissue (personal communication: G. Pynaert and J.Grooten, Dept Molecular Biomedical Research, Ghent University, Ghent, Belgium). The accumulation of allergenloaded $\mathrm{M} \phi$ in the spleen suggests that the M $\phi$ induce, locally, an indirect immunosuppressive effect. The additional findings that allergen-loaded $\mathrm{M} \phi$ induce an allergen-specific and longlasting suppressive response clearly demonstrated that allergen-specific suppressor lymphocytes have to be induced in the spleen. However, it cannot be fully excluded that the small numbers of $\mathrm{M} \phi$ in the lungs are also responsible for the induction of suppressor T-cells. M $\phi$ have to be activated to produce high levels of IL-10 that, in turn, is essential to suppress OVA-induced airway inflammation [21]. Since OVAinduced airway inflammation is suppressed even 4 weeks after i.v. administration of $\mathrm{M} \phi$ and it is rather hypothetical that they will still produce high levels of IL-10 at this time, the present data supports a role for allergen-specific suppressor lymphocytes induced by allergen-loaded $\mathrm{M} \phi$ in the spleen.
Furthermore, the pivotal role of donor-M $\phi$-derived IL-10 [21] does not suggest a role for resident $\mathrm{M} \phi$ responding to dead or apoptotic administered allergen-loaded $\mathrm{M} \phi$.

After treatment with allergen-loaded $M \phi$, differential effects were observed dependent on the examined parameters (fig. 3). This is in agreement with previous observations [21]. ISSODN-stimulated OVA-M $\phi$ suppress airway inflammation more effectively compared with unstimulated OVA-M $\phi$ or LPS-stimulated OVA-M $\phi$. This suggests that activation with ISS-ODN is needed for an effective induction of allergenspecific suppressor lymphocytes by OVA-M $\phi$ in the spleen. As activation of $\mathrm{M} \phi$ is not required for suppression of serum OVA-specific IgE levels (fig. 3), it can be speculated that allergen-loaded $\mathrm{M} \phi$ suppress allergen-induced airway manifestations via, at least, two different mechanisms of which one is IL-10 dependent [21]. OVA-induced airway hyperresponsiveness was measured using the Penh method, the authors would like to stipulate that Penh values may not correlate with changes in pulmonary resistance [32].

Most presumably a T-cell subset is involved, as the IL-10 production by OVA-M $\phi$ upon recognition of OVA-specific Tcells in vitro, is dependent on major histocompatibility complex class II/T-cell receptor interaction [20]. Upon allergen inhalation, the suppressive T-lymphocyte subset will be allergenspecifically activated (fig. 2) and, thereby, suppresses the Th2-lymphocyte mediated allergic airway inflammation and AHR. These data indicate that therapy with allergen-loaded $\mathrm{M} \phi$ could be used to suppress airway inflammation in an allergen-specific fashion. As a result, the immune system is still functional during therapy and is able to respond to intruders. This suggests that patients that are sensitised to multiple aeroallergens may require $M \phi$-based treatment with each allergen, either simultaneously or consecutively. However, it has been shown that multiple vaccinations with immature or mature antigen-presenting cells will not result in toxicity [33].

Although the exact suppressive T-cell subset remains to be elucidated, regulatory $\mathrm{T}$ (Treg) cells are likely candidates to be induced by allergen-loaded $M \phi$. Treg cells are typically induced in microenvironments with local high levels of IL-10 and antigen presenting cells that present foreign-antigens. Importantly, Treg cells are antigen-specific and have a memory phenotype [34]. Antigen-induced Treg cells play a crucial role in the maintenance of T-cell tolerance against foreign-antigens. This T-cell subset exhibits its suppressive activity by secreting the suppressive cytokine IL-10 (type 1 Treg cells) or TGF- $\beta$ (Th3 cells) [35]. Studies, using mouse models of allergic asthma, demonstrated that allergen-specific Treg cells can mediate the suppression of allergen-induced airway manifestations [36-38]. In the current study's model no increase of IL10 levels in the BALF after M $\phi$-treatment and subsequent OVA-inhalation challenge was found (data not shown). This suggests that OVA-M $\phi$ induce a suppressor-lymphocyte subset other than type 1 Treg cells.

The localisation of the allergen-loaded M $\phi$ in the spleen further supports the concept that Treg cells are induced. Although a few CMFDA-labelled M $\phi$ were detectable in the T-cell area, most ( $90 \%$ ) CMFDA-labelled $\mathrm{M} \phi$ were localised in the marginal zones of the spleen. Previously, it was demonstrated 
that in the marginal zone of the spleen antigen-presenting $\mathrm{M} \phi$, together with marginal zone B-cells and natural killer T-cells that likely secrete suppressive cytokines such as IL-10 and TGF- $\beta$, create a microenvironment that induces antigenspecific Treg cells $[39,40]$. In the current study's model, ISSODN-stimulated $\mathrm{M} \phi$ migrate to the marginal zones of the spleen and present, there, the allergen to lymphocytes. Since these M produce high levels of IL-10 [21], it can be hypothesised that a microenvironment is created in which allergen-specific Treg cells could be induced. Experiments in which splenocytes from tolerised mice are transferred to sensitised recipient mice are in progress to establish which suppressor-lymphocyte subset is induced upon interaction with allergen-loaded $\mathrm{M} \phi$.

Together, it was demonstrated that allergen-loaded macrophages are able to induce, besides direct suppression, an indirect suppression of airway manifestations of asthma in a mouse model. It can be speculated that allergen-loaded macrophages migrate to the spleen and present, locally, the allergen to the immune system while secreting interleukin-10. This causes a microenvironment in which an allergen-specific and long-lasting immunosuppressive response is induced. During the effector-phase, this immunosuppressive response suppresses allergen-induced airway manifestations. The role of macrophages in asthma pathology in general and the specific importance of macrophage-induced immunosuppressive memory responses against asthma manifestations may lead to novel strategies to induce stable suppression of allergenspecific T-helper type 2 responses.

\section{ACKNOWLEDGEMENTS}

The authors would like to thank M.A. Bloksma for enthusiastic support and suggestions.

\section{REFERENCES}

1 Robinson DS, Hamid Q, Ying S, et al. Predominant TH2like bronchoalveolar T-lymphocyte population in atopic asthma. N Engl J Med 1992; 326: 298-304.

2 Romagnani S. Human TH1 and TH2 subsets: regulation of differentiation and role in protection and immunopathology. Int Arch Allergy Immunol 1992; 98: 279-285.

3 Peters-Golden M. The alveolar macrophage: the forgotten cell in asthma. Am J Respir Cell Mol Biol 2004; 31: 3-7.

4 Gordon S. Alternative activation of macrophages. Nat Rev Immunol 2003; 3: 23-35.

5 Laskin DL, Weinberger B, Laskin JD. Functional heterogeneity in liver and lung macrophages. J Leukoc Biol 2001; 70: $163-170$.

6 Sibille Y, Reynolds HY. Macrophages and polymorphonuclear neutrophils in lung defense and injury. Am Rev Respir Dis 1990; 141: 471-501.

7 Hsieh CS, Macatonia SE, Tripp CS, Wolf SF, O'Garra A, Murphy KM. Development of TH1 CD4+ T cells through IL-12 produced by Listeria-induced macrophages. Science 1993; 260: 547-549.

8 Desmedt M, Rottiers P, Dooms H, Fiers W, Grooten J. Macrophages induce cellular immunity by activating Th1 cell responses and suppressing Th2 cell responses. J Immunol 1998; 160: 5300-5308.
9 Brewer JM, Richmond J, Alexander J. The demonstration of an essential role for macrophages in the in vivo generation of IgG2a antibodies. Clin Exp Immunol 1994; 97: 164-171.

10 Tang C, Inman MD, van Rooijen N, et al. Th type 1-stimulating activity of lung macrophages inhibits Th2mediated allergic airway inflammation by an IFN-gammadependent mechanism. J Immunol 2001; 166: 1471-1481.

11 Peterson JD, Herzenberg LA, Vasquez K, Waltenbaugh C. Glutathione levels in antigen-presenting cells modulate Th1 versus Th2 response patterns. Proc Natl Acad Sci U S A 1998; 95: 3071-3076.

12 Mills CD, Kincaid K, Alt JM, Heilman MJ, Hill AM. M-1/ M-2 macrophages and the Th1/Th2 paradigm. J Immunol 2000; 164: 6166-6173.

13 Goerdt S, Orfanos CE. Other functions, other genes: alternative activation of antigen-presenting cells. Immunity 1999; 10: 137-142.

14 Thepen T, Kraal G, Holt PG. The role of alveolar macrophages in regulation of lung inflammation. Ann $N$ Y Acad Sci 1994; 725: 200-206.

15 Strickland DH, Thepen T, Kees UR, Kraal G, Holt PG. Regulation of T-cell function in lung tissue by pulmonary alveolar macrophages. Immunology 1993; 80: 266-272.

16 Upham JW, Strickland DH, Bilyk N, Robinson BW, Holt PG. Alveolar macrophages from humans and rodents selectively inhibit T-cell proliferation but permit T-cell activation and cytokine secretion. Immunology 1995; 84: 142-147.

17 Holt PG, Oliver J, Bilyk N, et al. Downregulation of the antigen presenting cell function(s) of pulmonary dendritic cells in vivo by resident alveolar macrophages. J Exp Med 1993; 177: 397-407.

18 Thepen T, McMenamin C, Girn B, Kraal G, Holt PG. Regulation of IgE production in pre-sensitized animals: in vivo elimination of alveolar macrophages preferentially increases IgE responses to inhaled allergen. Clin Exp Allergy 1992; 22: 1107-1114.

19 Careau E, Bissonnette EY. Adoptive transfer of alveolar macrophages abrogates bronchial hyperresponsiveness. Am J Respir Cell Mol Biol 2004; 31: 22-27.

20 Janssen EM, Wauben MHM, Nijkamp FP, van Eden W, Van Oosterhout AJM. Immunomodulatory effects of antigen-pulsed macrophages in a murine model of allergic asthma. Am J Respir Cell Mol Biol 2002; 27: 257-264.

21 Vissers JLM, van Esch BCAM, Jeurink PV, Hofman GA, van Oosterhout AJM. Stimulation of allergen-loaded macrophages by TLR9-ligand potentiates IL-10-mediated suppression of allergic airway inflammation in mice. Respir Res 2004; 5: 21.

22 Nicklas W, Baneux P, Boot R, et al. Recommendations for the health monitoring of rodent and rabbit colonies in breeding and experimental units. Lab Anim 2002; 36: 20-42.

23 Roman M, Martin-Orozco E, Goodman JS, et al. Immunostimulatory DNA sequences function as T helper1-promoting adjuvants. Nat Med 1997; 3: 849-854.

24 Hessel EM, Van Oosterhout AJM, Hofstra CL, et al. Bronchoconstriction and airway hyperresponsiveness after ovalbumin inhalation in sensitized mice. Eur J Pharmacol 1995; 293: 401-412. 
25 De Bie JJ, Kneepkens M, Kraneveld AD, et al. Absence of late airway response despite increased airway responsiveness and eosinophilia in a murine model of asthma. Exp Lung Res 2000; 26: 491-507.

26 Van Oosterhout AJM, Van Esch B, Hofman G, et al. Allergen immunotherapy inhibits airway eosinophilia and hyperresponsiveness associated with decreased IL-4 production by lymphocytes in a murine model of allergic asthma. Am J Respir Cell Mol Biol 1998; 19: 622-628.

27 Pynaert G, Rottiers P, Haegeman A, Sehra S, Korf J, Grooten J. Antigen presentation by local macrophages promotes nonallergic airway responses in sensitized mice. Am J Respir Cell Mol Biol 2003; 29: 634-646.

28 Kupiec-Weglinski JW, Austyn JM, Morris PJ. Migration patterns of dendritic cells in the mouse. Traffic from the blood, and T cell-dependent and -independent entry to lymphoid tissues. J Exp Med 1988; 167: 632-645.

29 Andreesen R, Hennemann B. Adoptive immunotherapy with autologous macrophages: current status and future perspectives. Pathobiology 1991; 59: 259-263.

30 Mackensen A, Krause T, Blum U, Uhrmeister P, Mertelsmann R, Lindemann A. Homing of intravenously and intralymphatically injected human dendritic cells generated in vitro from CD34+ hematopoietic progenitor cells. Cancer Immunol Immunother 1999; 48: 118-122.

31 Eggert AA, Schreurs MW, Boerman OC, et al. Biodistribution and vaccine efficiency of murine dendritic cells are dependent on the route of administration. Cancer Res 1999; 59: 3340-3345.
32 Bates J, Irvin C, Brusasco V, et al. The use and misuse of Penh in animal models of lung disease. Am J Respir Cell Mol Biol 2004; 31: 373-374.

33 De Vries IJ, Lesterhuis WJ, Scharenborg NM, et al. Maturation of dendritic cells is a prerequisite for inducing immune responses in advanced melanoma patients. Clin Cancer Res 2003; 9: 5091-5100.

34 Weiner HL. The mucosal milieu creates tolerogenic dendritic cells and TR1 and TH3 regulatory cells. Nat Immunol 2001; 2: 671-672.

35 Maloy KJ, Powrie F. Regulatory T cells in the control of immune pathology. Nat Immunol 2001; 2: 816-822.

36 Akbari O, DeKruyff RH, Umetsu DT. Pulmonary dendritic cells producing IL-10 mediate tolerance induced by respiratory exposure to antigen. Nat Immunol 2001; 2: 725-731.

37 Akbari O, Freeman GJ, Meyer EH, et al. Antigen-specific regulatory $\mathrm{T}$ cells develop via the ICOS ICOS-ligand pathway and inhibit allergen-induced airway hyperreactivity. Nat Med 2002; 8: 1024-1032.

38 Zuany-Amorim C, Sawicka E, Manlius C, et al. Suppression of airway eosinophilia by killed Mycobacterium vaccae-induced allergen-specific regulatory T-cells. Nat Med 2002; 8: 625-629.

39 Faunce DE, Sonoda KH, Stein-Streilein J. MIP-2 recruits NKT cells to the spleen during tolerance induction. J Immunol 2001; 166: 313-321.

40 Streilein JW, Masli S, Takeuchi M, Kezuka T. The eye's view of antigen presentation. Hum Immunol 2002; 63: 435-443. 